\title{
Event-driven Modelling Method for Sub-assembly Intelligent Production Line
}

\author{
Guangzhou Diao ${ }^{1, a}$, Jing Rao ${ }^{1}$ and Jun Zhao ${ }^{1}$ \\ ${ }^{1}$ Shanghai Shipbuilding Technology Research Institute, 200032 Shanghai, China
}

\begin{abstract}
Focusing on the design of sub-assemble intelligent production line, an event-driven design method for production line was proposed. With the method, the manufacturing activity was defined as event, and then the relationships among events are analysed to define the input-output and execution behaviours digitally in each stage. Furthermore, the event-driven execution mechanism for multi-stage process was built to describe the production line in digital. The digital model of production line was conducted to explore the event behaviours, which will support the research about data-driven production line simulation in future work.
\end{abstract}

\section{Introduction}

Shipbuilding is a discrete type manufacturing, so the subassemble manufacturing is not conducted in the form of flow production like auto-industry. Recently, with the development of intelligent manufacturing, the new technical change will come into shipbuilding, and intelligent production line become the important direction for shipbuilding transformation and upgrading.

Sub-assembly is the typical structure in modern shipbuilding mode, which has the characteristics of large demands and variable types. Generally, the sub-assembly production contains many processes, including assemble, weld, repair, polish and back burning. In many enterprises, the production mode of sub-assembly is the combination of manual operation and robot operation. Some shipyards have developed the production line for sub-assemble.

Depending on the manufacturing technique of subassemble to improve the intelligent level, the production line of sub-assemble is designed. The digital model is established to support the data-driven simulation of production line.

\section{The mechanism of event-driven process control}

The mentioned event in this paper is defined as the series of job activity, including material transportation, material waiting, and job execution. With the concept, the event in manufacturing process can be described. First, the relevant events in process are defined listed in the Table 1.
Table 1. The definition of relevant events.

\begin{tabular}{|c|c|c|c|}
\hline Concept & Ico & Symbol & Descriptions \\
\hline $\begin{array}{c}\text { Event } \\
\text { waiting }\end{array}$ & $\square$ & $B P_{i}$ & $\begin{array}{c}\text { The waiting behaviour in } \\
\text { one process }\end{array}$ \\
\hline $\begin{array}{c}\text { Keep } \\
\text { waiting }\end{array}$ & $\sum D$ & $B S_{i}$ & $\begin{array}{c}\text { The waiting behaviour in } \\
\text { next process }\end{array}$ \\
\hline $\begin{array}{c}\text { Event } \\
\text { execution }\end{array}$ & $\sum \nabla$ & $F P_{i}$ & $\begin{array}{c}\text { The execution behaviour in } \\
\text { one process }\end{array}$ \\
\hline Interval & $P I_{i}$ & $\begin{array}{c}\text { The time between two } \\
\text { execution behaviours of } \\
\text { events }\end{array}$ \\
\hline $\begin{array}{c}\text { Event } \\
\text { time }\end{array}$ & $M P_{i}$ & $\begin{array}{c}\text { The time for one event to be } \\
\text { executed }\end{array}$ \\
\hline
\end{tabular}

It is noted that the behaviours out of execution are all treated as waiting behaviours, including the transportation behaviours. A case with three stations is analysed to describe the proposed method shown in Fig.1.

In Fig. $1(a)$, the waiting behavior occurred after $(i-1)$ station and before $\mathrm{i}$ station, which included 3 event behaviors, written as Ei. The mathematical model can be described as follows.

$$
E_{i}=\left\{B S_{i}, F P_{i}, B P_{i}\right\}
$$

In addition, the waiting stage included material transportation and machining waiting. The machining stage included machining arrangement and machining execution. The waiting after machining included postprocessing after machining and transportation waiting. 


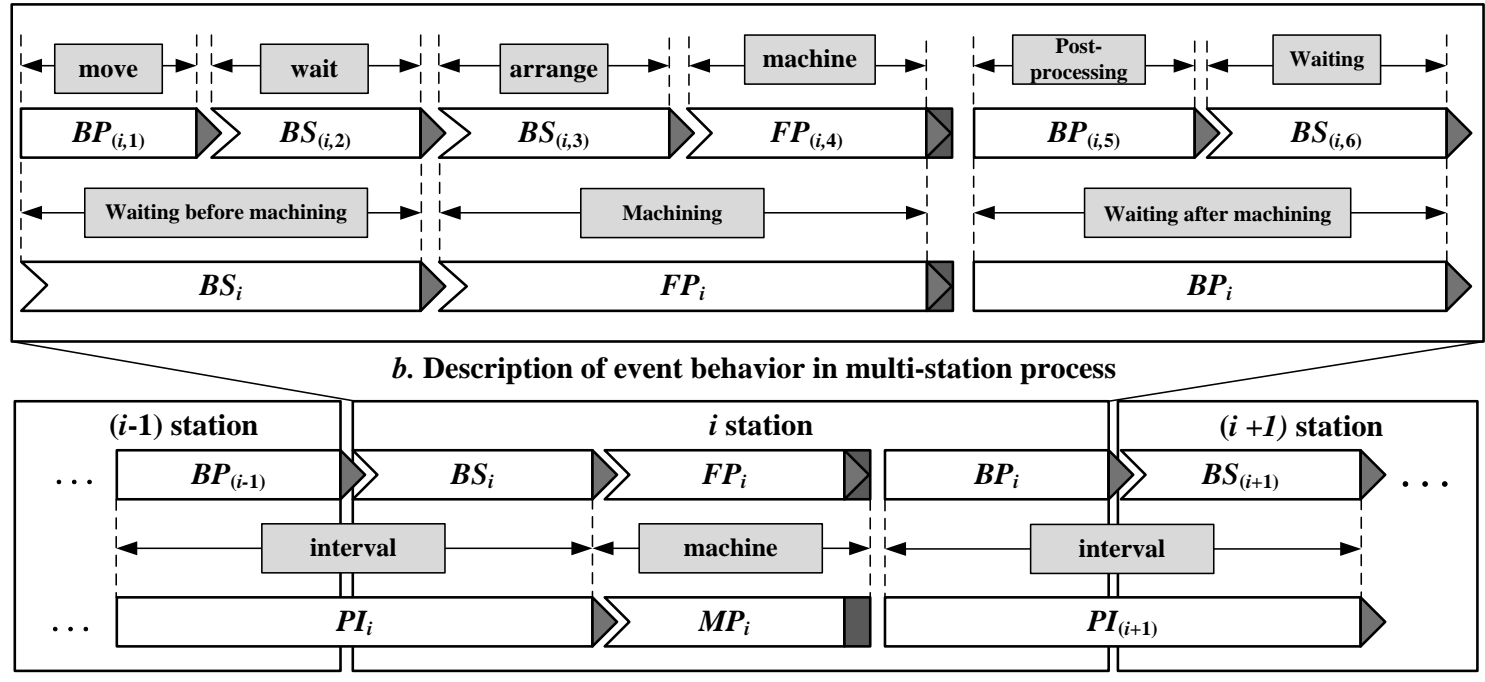

a. Description of multi-station process

Figure 1 The graphical description of multi-station

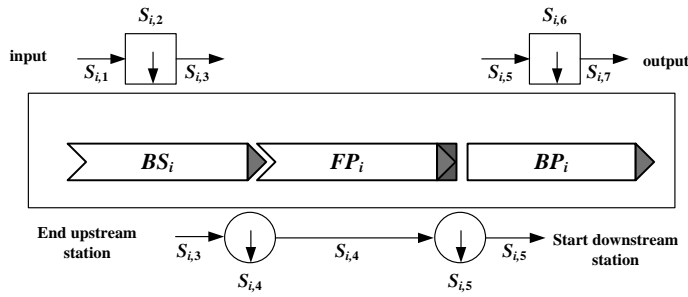

Figure 2 Event behavior analysis in manufacturing process

In Fig. $2, S_{i, j}$ denoted the $j^{\text {th }}$ event in $i^{t h}$ station. Each event behavior included 3 trigger events, which were input, execution and output. The input event is triggered by the behavior in upstream station. The input event triggered the execution event. When the execution was completed, the output event was triggered. In the same way, the event-driven execution mechanism in multistation was formed. The method was generally conducted by a series of events.

\section{The event behaviour analysis of sub- assembly production line}

\subsection{The process flow of sub-assemble manufacturing}

The manufacturing of sub-assemble generally contained 6 stations, which were loading, assembling, welding, repairing, back burning and baiting etc. The function of each station was listed as follows.

(1) Loading. It was used to place the sheets of all workpieces for sub-assemble. The execution event was to transport the workpiece to assembly station by electromagnetic lifter. The involved equipment was electromagnetic lifter.

(2) Assembly. It was used to group, spot weld and transport. Firstly, the baseplate and rib plate were grouped to conduct spot weld. After assembly, the workpieces were transported to welding area. The involved equipment was roller bed and plot weld equipment.
(3) Weld. The weld robots were used to complete welding. The execution process was that the visual identity was utilized to scan the structure of workpiece. Then the process parameters were selected depending on the scanned structure. Following, the welding work was conducted. The involved equipment was roller bed, crane, robots, visual system and welding devices etc.

(4) Repair. The assisted jobs (welding slag clear, welding check, polish) were conducted to support welded sub-assemble structure. The involved equipment was roller bed, polish device.

(5) Back burn. The process was to amend the deformation for sub-assemble and release the stress. The involved equipment was back burning device.

(6) Bait. The manufactured sub-assemble was baited in the process. The involved equipment was electromagnetic lifter.

\subsection{The event behaviour analysis of sub- assemble production line}

The 6 working areas mentioned above are treated as the production station and the extracted event-behaviors in each station are listed.

The operating mechanism between event and behavior are displayed in Fig. 3. In addition, the simulation are conducted to verify the proposed method shown in Fig.4.

In Fig 3, the proposed method can describe the subassembly production line digitally. With the development of CPS, the 'digital twin' becomes the important issue in shipbuilding. A digital environment with virtually and reality is the basis of popularization and application of intelligent manufacturing technology. Therefore, the proposed modeling method can provide an appropriate solution for building a data-driven digital environment for sub-assembly production line. 
Table 2 Event behavior of sub-assemble production line

\begin{tabular}{|c|c|c|c|c|}
\hline Station & Behavior & Symbol & Set & Description \\
\hline \multirow{2}{*}{ load } & Waiting before load & $B P_{1}$ & \multirow{2}{*}{$E_{1}$} & \multirow{2}{*}{$\begin{array}{l}\text { Depending production requirement, the required } \\
\text { materials were transported to load station and } \\
\text { waiting. Then the loading arrangement and } \\
\text { execution were conducted to complete loading. }\end{array}$} \\
\hline & Loading execution & $F P_{1}$ & & \\
\hline \multirow{3}{*}{ assembly } & Waiting before assembly & $\mathrm{BP}_{2}$ & \multirow{3}{*}{$E_{2}$} & \multirow{3}{*}{$\begin{array}{l}\text { After loading, the materials were transported to } \\
\text { assembly station and waiting. Then the assembly } \\
\text { arrangement and execution were conducted to } \\
\text { complete assemble. }\end{array}$} \\
\hline & Assembly execution & $F P_{2}$ & & \\
\hline & Waiting after assembly & $B S_{2}$ & & \\
\hline \multirow[b]{2}{*}{ weld } & $\mathrm{Wa}$ & $B P_{3}$ & \multirow[b]{2}{*}{$E_{3}$} & \multirow{2}{*}{$\begin{array}{l}\text { After assemble, the materials were transported to } \\
\text { welding station. With the welding waiting, welding } \\
\text { arrangement and welding execution operation, the } \\
\text { welding job was completed. }\end{array}$} \\
\hline & Welding execution & $\mathrm{FP}_{3}$ & & \\
\hline \multirow[b]{2}{*}{ repair } & Waiting be & $\mathrm{BP}_{4}$ & \multirow[b]{2}{*}{$E_{4}$} & \multirow{2}{*}{$\begin{array}{l}\text { After welding, the materials were transported to } \\
\text { repair station. With the repairing waiting, repairing } \\
\text { execution operations, the repairing job was } \\
\text { completed. }\end{array}$} \\
\hline & Repair execution & $\mathrm{FP}_{4}$ & & \\
\hline \multirow{2}{*}{$\begin{array}{l}\text { back } \\
\text { burn }\end{array}$} & $\begin{array}{l}\text { Waiting before back } \\
\text { burning }\end{array}$ & $B P_{5}$ & \multirow{2}{*}{$E_{5}$} & \multirow{2}{*}{$\begin{array}{l}\text { After repairing, the materials were transported to } \\
\text { back burning station. The back burning waiting and } \\
\text { execution were conducted to complete back } \\
\text { burning. }\end{array}$} \\
\hline & Back burning execution & $F P_{5}$ & & \\
\hline \multirow{2}{*}{ bait } & Waiting before baiting & $B P_{6}$ & \multirow{2}{*}{$E_{6}$} & \multirow{2}{*}{$\begin{array}{l}\text { Finally, the machined workpiece was baited in this } \\
\text { station. }\end{array}$} \\
\hline & Baiting execution & $F P_{6}$ & & \\
\hline
\end{tabular}

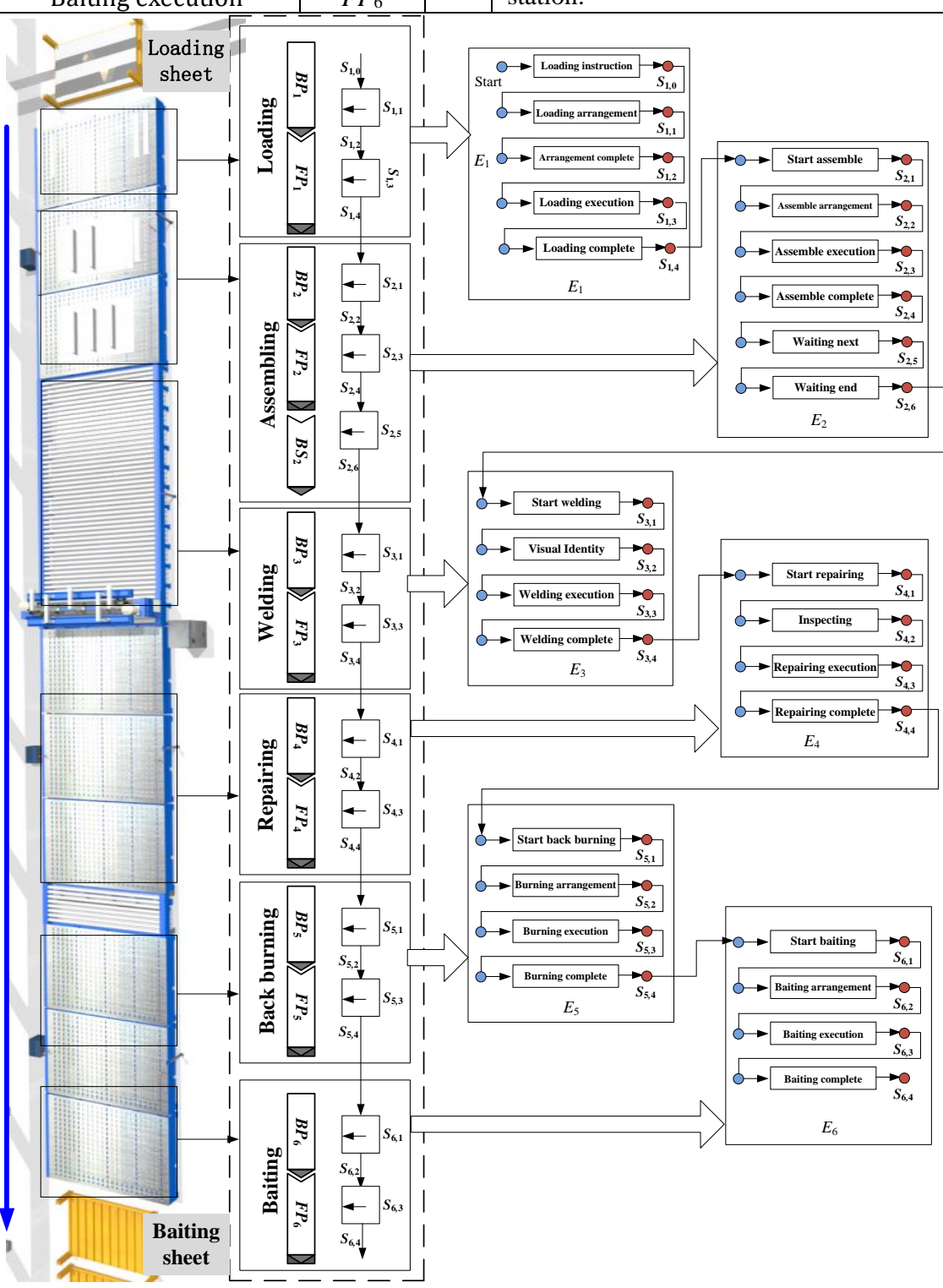

Figure 3 The event behaviour relationships in sub-assembly production line 


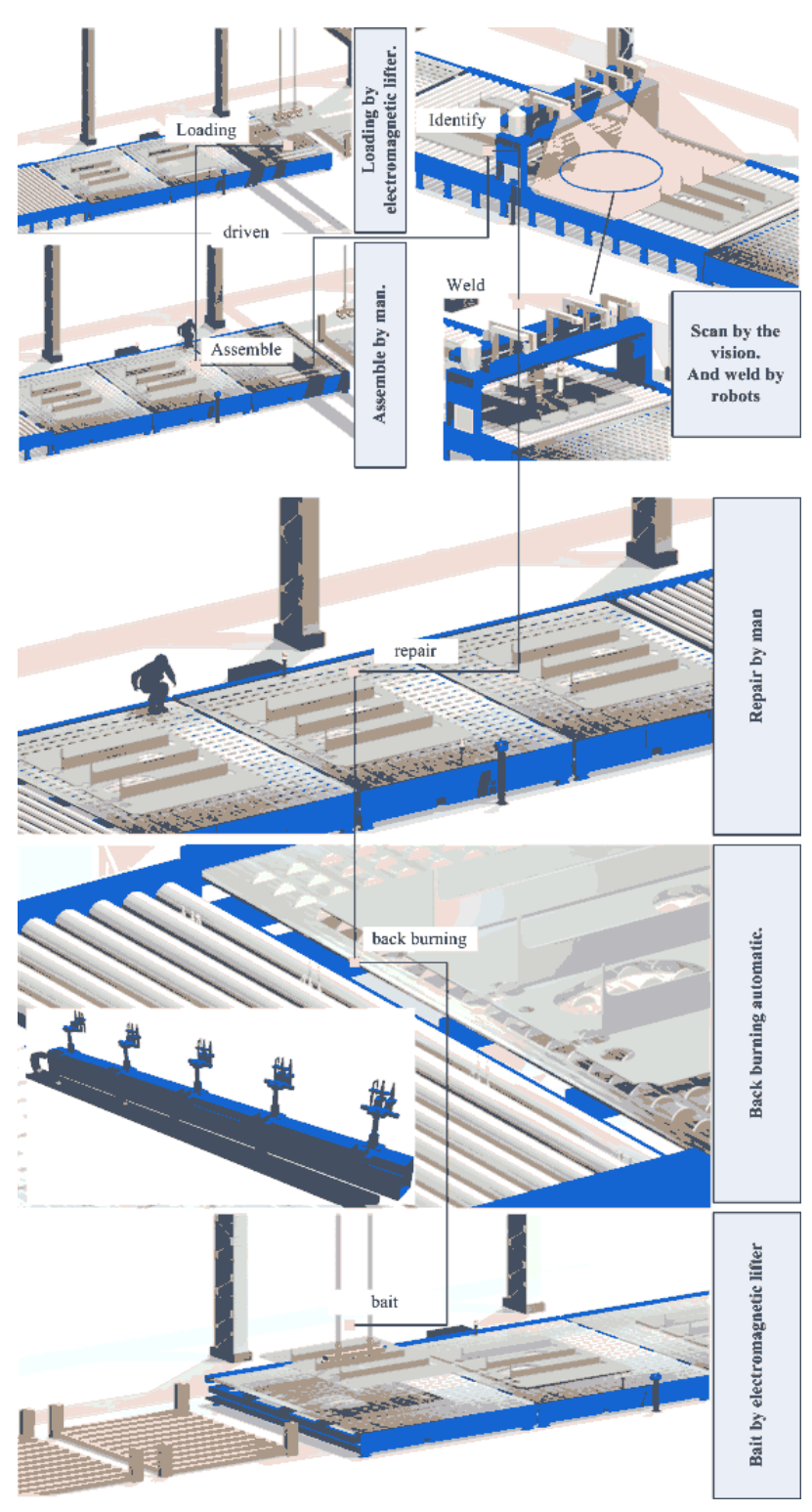

Figure4 The simulation of production line with proposed method

\section{Conclusions}

On the basis of production technology, an intelligent manufacturing-oriented digital modeling method for production line was proposed, which could provide a new solution for constructing simulation environment of sub-assembly production line. With the method, the subassembly manufacturing process could be described digitally. Then the practical production data were used to simulate production line, and the results showed that the established digital model was appropriate.

\section{References}

1. JIANG PY and CAO W.An RFID-Driven Graphical Formalized Deduction for Describing the TimeSensitive State and Position Changes of Work-inProgress Material Flows in a Job-Shop Floor [J],
Trans. of the ASME: J of Manufacturing Science and Engineering, Vol.135, No.3, June 2013

2. ZHANG Y F, XI D, SUN SD. Task-driven manufacturing cloud service proactive discovery and optimal configuration method [J]. International Journal of Advanced Manufacturing Technology, 2016, 84:29-45.

3. PARK JG, YI MS, HA YS, et al. Development of full automatic re-design system for sub-assembly part fabrication of ship blocks [C]// Development of Full Automatic Re-Design System for SubAssembly Part Fabrication of Ship Blocks (ICCAS, 2007). Trieste, Italy, 2007:1-5.

4. ZHOU YF, Design of auto generating tool of part sub assembly drawing $[\mathrm{J}]$. Ship \& Ocean Engineering, 2014, 43(3):68-70.

5. YU LS, The research and implementation of optimal design of ship panel line [D]. 2007, Shanghai Jiaotong University. 